\title{
The tubB $\alpha$-tubulin gene is essential for sexual development in Aspergillus nidulans
}

\author{
Karen E. Kirk and N. Ronald Morris \\ Department of Pharmacology, University of Medicine and Dentistry of New Jersey, Robert Wood Johnson Medical School \\ |at Rutgers\}, Piscataway, New Jersey, 08854 USA
}

\begin{abstract}
The filamentous fungus Aspergillus nidulans has two genes encoding $\alpha$-tubulin, tubA and tubB. Mutational analysis of $t u b A$ has demonstrated that the $t u b A$ gene is essential for mitosis and nuclear migration. In this study we have deleted the $t u b B$ gene by replacing it with a selectable marker and have named this new allele $\operatorname{tu} b B \Delta$. The results demonstrate that the $t u b B$ gene is not required for vegetative growth or asexual reproduction, nor is it required for the initiation or early stages of sexual differentiation. Deletion of tubB, however, completely prevents ascosporogenesis, because tubBA strains produce no sexual spores when self-crossed. These strains produce viable ascospores when outcrossed to $\operatorname{tub} B^{+}$strains, indicating that the tubBA mutation is recessive. We have studied the cytology of sexual development in wild-type strains and in the tubB mutant and have observed that tubBA. strains develop normally to the stage of ascus formation. However, only a single nuclear mass is observed in the $t u b B \Delta$ ascus, indicating that either the two zygotic haploid nuclei are blocked in karyogamy or that karyogamy occurs but the resulting diploid nucleus is subsequently blocked in meiosis $\mathrm{I}$.
\end{abstract}

[Key Words: Multigene family; ascospore formation; meiosis; reverse genetics]

Received July 17, 1991; revised version accepted September 11, 1991.

A multigene family can empower its members differentially at specific times and places during development, thereby enhancing the functional diversity of the genes. Most eukaryotes possess more than one gene for $\alpha$ - and $\beta$-tubulins, and these multiple copies frequently display intricate patterns of expression throughout development (for review, see Raff 1984). Such a pattern may reflect the specific temporal or spatial requirement of an organism for one gene rather than another. After losing one member of a tubulin multigene family, some organisms exhibit no phenotype until a specific stage of development or differentiation is reached. One remarkable example of such a situation has been described extensively for the four-membered $\beta$-tubulin family in Drosophila melanogaster, where the $\beta_{2}$ gene is paramount during spermatid differentiation but is dispensable at all other times (Kemphues et al. 1979, 19821.

Throughout development of the filamentous fungus Aspergillus nidulans, a tubulin gene family can have many opportunities to display its multiformity. The organism undergoes distinct asexual and sexual developmental stages, each involving the formation of structures containing many differentiated cell types. The multinucleate hyphae propagate in the vegetative state and can be induced to form the multicellular asexual reproductive apparatus, the conidiophore. This developmental process has been well studied by Timberlake and co-workers, and involves the induced expression of $>1000$ mRNAs (Timberlake 1980), several of which have been characterized (for review, see Timberlake 1990). At about the time that conidiation ceases, sexual differentiation commences. This developmental stage involves the appearance of at least five different cell types that ultimately form the fruiting body (cleistothecium) harboring the sexual spores (for review, see Champe and Simon 1991). Little is known about the external factors that induce sexual development or the genes that play a role in this process.

A. nidulans has two genes encoding $\alpha$-tubulin, two encoding $\beta$-tubulin (Morris et al. 1984), and one that encodes $\gamma$-tubulin, a newly identified member of the tubulin gene superfamily (Oakley and Oakley 1989). Mutations in the ben $A \beta$-tubulin gene cause an inhibition of nuclear division and nuclear migration during vegetative growth (Oakley and Morris 1980, 1981). Expression of the second $\beta$-tubulin gene, tubC, is induced during asexual development (May and Morris 1988), and the gene product normally functions during this process (Weatherbee et al. 1985). However, null mutations and molecular gene disruption have demonstrated that the $t u b C$ gene is not essential for conidiation or any other stage of the life cycle (May et al. 1985; Weatherbee et al. 1985). Mutations in the $t u b A \alpha$-tubulin gene that suppress mutations in the ben $A \beta$-tubulin gene have been identified 
(Oakley et al. 1987). Analysis of these tubA mutants, as well as those generated by molecular gene disruption (Doshi et al. 1991), has demonstrated that like the ben $A$ gene product, tubA $\alpha$-tubulin is involved in nuclear division and nuclear migration. A second gene encoding $\alpha$-tubulin, $t u b B$, is expressed during vegetative growth, but the gene product constitutes only a small fraction of the total $\alpha$-tubulin (Weatherbee and Morris 1984). Classic genetic studies have not identified any mutations in the $t u b B$ gene.

The present study was initiated to determine unambiguously the role of the $A$. nidulans $t u b B$ gene throughout development of the organism. Recently, the $t u b B$ gene has been cloned and sequenced (Doshi et al. 1991), enabling us to utilize reverse genetics to examine the effect of deleting the coding region. We show that strains lacking the $t u b B$ gene $(t u b B \Delta)$ exhibit no significant phenotype during vegetative growth or asexual sporulation. The tubB $\Delta$ mutation, however, completely prevents ascosporogenesis. We present cytological studies of sexual development in $A$. nidulans and demonstrate that tubBS strains initiate sexual development normally but are blocked severely at a stage prior to the first meiotic division.

\section{Results}

Deletion of the tubB gene

We chose to inactivate the $t u b B$ gene by deleting the coding region so that the effect on the cell could be unequivocally attributed to the loss of $t u b B$ function. A plasmid (pKK2.1.3) was constructed that was designed to replace the tubB-coding region (except for the $3^{\prime}$-terminal $20 \%$ ) with the Neurospora pyr4 selectable marker upon site-specific integration of the plasmid at the $t u b B$ locus (see Materials and methods). We used this plasmid to transform an $A$. nidulans pyrG89 strain to uridine prototrophy. All transformants gave rise to conidia (uninucleate haploid asexual spores) that were viable on selective media, indicating that if the $t u b B$ gene had been deleted in any of these transformants, the deletion was not a lethal event. To determine the site of plasmid integration, genomic DNA from six arbitrarily chosen transformants was subjected to Southern blot analysis. Hybridization to a probe containing the $3^{\prime}$ end of $t u b B$ should reveal the predicted restriction fragment polymorphisms between wild-type DNA and transformant DNA in which the tubB-coding region had been successfully replaced with the pyr4 selectable marker (Fig. 1A). The expected patterns for plasmid integration at the $t u b B$ locus were observed for five of the transformants tested, and the data from one of these are presented (Fig. 1B). These results indicated that gene replacement at the $t u b B$ locus by transformation with $\mathrm{pKK} 2.1 .3$ was a relatively common event.

We then verified that the $t u b B$-coding region was actually deleted from these strains and that part of the tubB-coding region had not translocated to a different region of the genome, an event that is unlikely but none- theless may have gone undetected in the above analysis. A DNA probe containing the tubB-coding region, but lacking the $3^{\prime}$-terminal $20 \%$, was hybridized to total genomic DNA from three of the transformants having sitespecific integration of the gene replacement plasmid and from the one transformant whose plasmid integrated elsewhere in the genome. No hybridization was detected to DNA from those transformants that had undergone a successful gene replacement event (Fig. 2), indicating that the tubB-coding region was absent from these strains. These data demonstrated that $t u b B$ is not an essential gene.

\section{Phenotype of tubB $\Delta$ strains}

We examined the effect of deleting the $t u b B$ gene on all stages of the $A$. nidulans life cycle: vegetative hyphal growth, and asexual and sexual sporulation. A. nidulans grows vegetatively on solid media by apical extension of the hyphae, and growth rate can therefore be determined by measuring the increase in colony diameter over time. We compared the growth rates of different $t u b B^{+}$and tubB $\Delta$ strains and have presented typical data (Table 1). To eliminate differences in growth rate as a result of nutritional requirements, both strains used in this study were prototrophs. Under optimal growth conditions in this experiment $\left(37^{\circ} \mathrm{C}\right.$ and no benomyl), the growth rate of the $t u b B \Delta$ strain was not significantly different from that of the wild-type strain. We also compared the growth rates of these two strains under conditions known to affect microtubule stability (Table 1). Many $A$. nidulans tubulin mutants have been identified with either increased sensitivity or resistance to the antimicrotubule drug benomyl, and some of these tubulin mutants are also cold or heat sensitive (Sheir-Neiss et al. 1978; Oakley et al. 1987). We examined the effect of benomyl on the growth rate of the tubBA mutant over a range of drug concentrations. Growth of the $t u b B \Delta$ strain was not significantly more sensitive to benomyl than wild type, nor was it more resistant to high drug concentrations. We also tested the temperature sensitivity of the tubBD strain by measuring the hyphal growth rate at $25^{\circ} \mathrm{C}$ and at $42^{\circ} \mathrm{C}$ and found no significant difference from wild type. Similar tests for the effect of the tubB $\Delta$ mutation on asexual sporulation indicated that the conidial yield and viability were unaffected in the tubBA mutant, even when conidiation took place at $25^{\circ} \mathrm{C}$ or at $42^{\circ} \mathrm{C}$, or in the presence of benomyl (data not shown).

We then examined the ability of the tubB $\Delta$ mutant to undergo sexual development. A. nidulans is homothallic; therefore, a single conidium normally has the potential to form hyphae that ultimately become sexually fertile, yielding identical meiotic progeny. Alternatively, when conidia from two different strains are coinoculated, self-fertilization of either parent may still occur, but an outcross between the two parents can also take place and will result in the formation of recombinant progeny. In any case, sexual maturity can be visually monitored by the appearance of $0.1-$ to $0.2-\mathrm{mm}$-diameter fruiting bodies, called cleistothecia, which encase the 
A
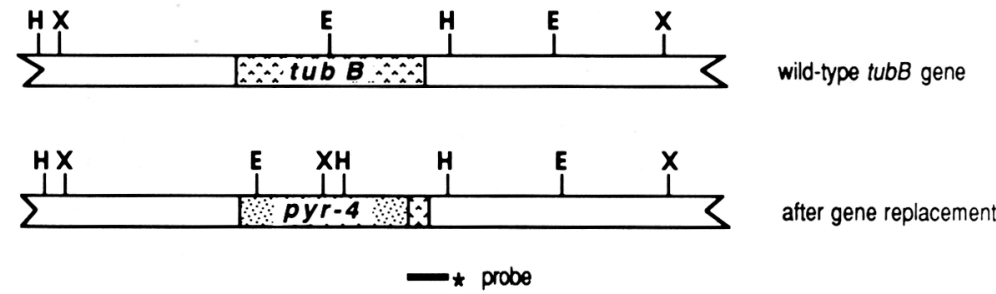

Figure 1. Gene replacement at the $t u b B$ locus. (A) Schematic diagram illustrating the positions of $E c o R I(E)$, HindIII (H), and $X h o I(X)$ restriction enzyme sites in the wild-type $t u b B$ gene and the predicted new positions after $80 \%$ of the tubBcoding region is replaced with the pyr 4 selectable marker. The radiolabeled probe used for the Southern blot was made to a flanking region common to both alleles and is indicated by a solid bar, which represents $\sim 400 \mathrm{bp}$. (B) Genomic Southern blot analysis of wild-type DNA $(w t)$ and DNA from one transformant that had site specifically integrated $\mathrm{pKK} 2.1 .3(\Delta)$. The sizes of hybridizing fragments from wild-type and tubB DNA, respectively, are 3.0 and 4.3 $\mathrm{kb}$ upon digestion with EcoRI, 5.0 and $1.1 \mathrm{~kb}$ upon digestion with HindIII, and 9.1 and $4.5 \mathrm{~kb}$ upon digestion with $\mathrm{XhoI}$.

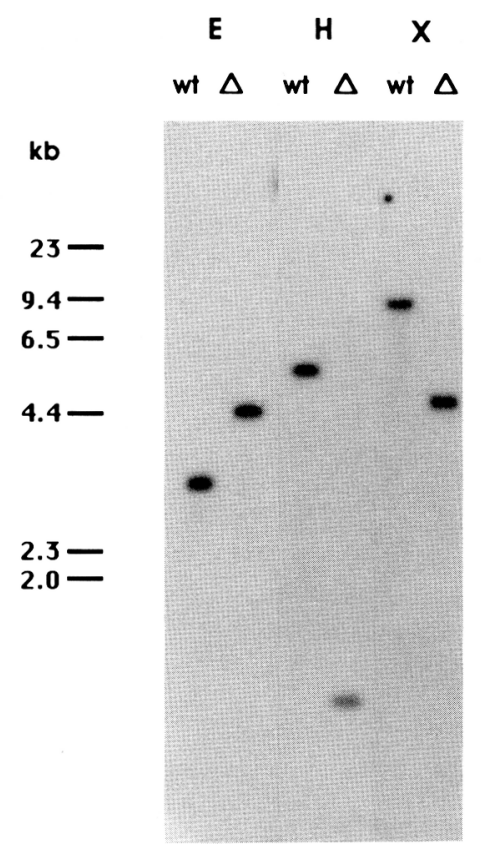

ascospores formed within. The size of cleistothecia can vary greatly, and the number of ascospores differs proportionately; an average cleistothecium contains $\sim 1 \times 10^{4}$ to $5 \times 10^{4}$ ascospores.

To examine the ability of a tubB $\triangle$ mutant to undergo self-fertilization, conidia were inoculated onto solid media, and colonies were grown and allowed to develop to sexual maturity. The tubB $\Delta$ mutant formed a typical number of morphologically normal cleistothecia. Nevertheless, when the contents were studied microscopically, no sexual spores were found in hundreds of cleistothecia examined (Table 2). We then examined the abil-

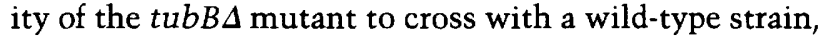
reasoning that ascospore formation would occur if the $t u b B \Delta$ allele were recessive. Conidia from the $t u b B \Delta$ mutant and from a $t u b B^{+}$strain (GR1) were mixed on solid media, and hyphae grown and allowed to reach sexual maturity. When the contents of arbitrarily chosen cleistothecia were analyzed for parental origin, three classes of cleistothecia were observed: those containing recombinant progeny; those containing progeny having only the GR1 parental phenotype; and cleistothecia, which contained no ascospores, indicative of the abor-

tive self-fertilization of the $t u b B \Delta$ parent. The ascospore yield and viability from four cross-fertilized cleistothecia were determined and found to be essentially normal, thereby indicating that the $t u b B \Delta$ allele is recessive during sexual development (Table 2).

The defect in sexual development is directly due to the loss of the tubB gene

To verify that the defect in ascosporogenesis was directly caused by the loss of the $t u b B$ gene and not by an extragenic mutation, we determined whether uridine prototrophy, conferred by the pyr4 gene replacement marker, cosegregated with the self-sterile phenotype in a cross between a tubB $\Delta:: p y r 4^{+}$; pyrG89 strain and a tubB ${ }^{+}$; pyrG89 strain. Fifty segregants chosen arbitrarily from a single recombinant cleistothecium were screened for their ability to grow in the absence of uridine and for their ability to produce ascospores from a self-cross $(\mathrm{Ta}-$ ble 3). All progeny that were auxotrophic for uridine also produced ascospores, and those progeny that grew in the absence of uridine were self-sterile, indicating that the 


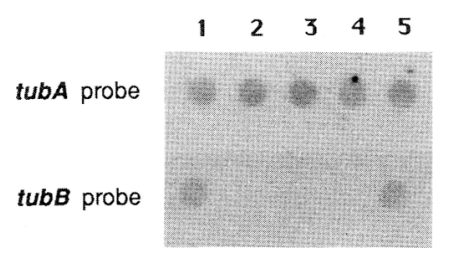

Figure 2. Loss of the $t u b B$-coding region. Equal amounts of total genomic DNA from wild-type (lane 1), three transformants identified previously as having site specifically integrated the gene replacement plasmid (lanes 2-4), and from one transformant whose plasmid integrated elsewhere in the genome (lane 5) were dotted onto duplicate nitrocellulose filters and probed with either radiolabeled DNA from the $t u b A$-coding region, as a control for DNA quantity, or from the $5^{\prime} 80 \%$ of the $t u b B$ coding region.

defect in ascosporogenesis was closely linked /within 2

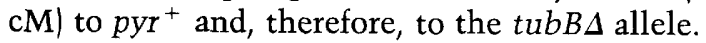

We also tested the ability of a wild-type $t u b B$ genomic clone to complement the tubBS mutation. This clone contained $2.8 \mathrm{~kb}$ upstream of the transcription initiation site (Doshi et al. 1991) and was therefore likely to contain any regulatory elements necessary for expression. A plasmid (pKK2.124.1) was constructed carrying this $t u b B$ genomic clone and the Aspergillus $\arg B$ gene and was used to transform a tubBD; argB2 strain to arginine prototrophy. Individual transformants were tested for their ability to produce ascospores in a self-cross. Of the 10 transformants tested, 5 produced ascospores in a selfcross, and all 10 transformants that received a control plasmid carrying only the $\arg B$ gene retained the $\operatorname{tabB\Delta }$ mutant phenotype. Because arginine-independent transformants often arise as a result of $\arg B 2$ gene conversion to $\arg B^{+}$without plasmid integration, DNA from the 10 recipients of pKK2.124.1 was subjected to Southern blot analysis to determine whether the lack of complementation in five transformants was the result of a lack of plasmid integration (Fig. 3). Of those transformants that

Table 1. Comparison of vegetative growth rates

\begin{tabular}{|c|c|c|c|}
\hline \multicolumn{2}{|c|}{ Growth condition } & \multirow[b]{2}{*}{$\operatorname{tub} B^{+a}$} & \multirow[b]{2}{*}{$\operatorname{tub} B \Delta^{\mathrm{b}}$} \\
\hline $37^{\circ} \mathrm{C}$ & benomyl $(\mu \mathrm{g} / \mathrm{ml})$ & & \\
\hline & 0 & $16.0 \pm 1.5$ & $15.0 \pm 0.5$ \\
\hline & 0.25 & 15.5 & 13.5 \\
\hline & 0.50 & 9.0 & 7.0 \\
\hline & 0.70 & 3.0 & 3.0 \\
\hline & 0.90 & 1.0 & 0.5 \\
\hline & 1.20 & $N^{e}$ & NG \\
\hline $25^{\circ} \mathrm{C}$ & & $6.5 \pm 1.0$ & $6.0 \pm 1.5$ \\
\hline $42^{\circ} \mathrm{C}$ & & $8.5 \pm 1.0$ & $8.5 \pm 0.5$ \\
\hline
\end{tabular}

Recorded values represent the average from three measurements in millimeters (to the nearest $0.5 \mathrm{~mm}$ ) grown per day \pm S.D., starting 1 day after inoculation of conidia.

${ }^{a}$ Strain KK3.43.1.

bstrain KK2.150.1.10.

e(NG) No growth.
Table 2. Effect of tubB $\Delta$ on sexual fertility

\begin{tabular}{|c|c|c|c|}
\hline & \multicolumn{2}{|c|}{ Self-fertilization } & \multirow{2}{*}{$\frac{\text { Cross-fertilization }}{t u b B^{+c} \times t u b B \Delta^{b}}$} \\
\hline & $t u b B^{+a}$ & $\operatorname{tubB} \Delta^{\mathrm{b}}$ & \\
\hline Ascospore yield ${ }^{d}$ & $3.1 \pm 1.3 \times 10^{4}$ & 0 & $6.7 \pm 2.3 \times 10^{4}$ \\
\hline viability ${ }^{\mathrm{e}}$ & $93.0 \pm 2.5$ & - & $81.0 \pm 2.0$ \\
\hline
\end{tabular}

astrain GR5.

${ }^{\mathrm{b}} \mathrm{S}$ train KK2.70.7.

"Strain GR1.

${ }^{d}$ Recorded values represent the average from four cleistothecia of the number of ascospores per cleistothecium \pm s.D. For the $t u b B \Delta$ self-cross, the entire contents from hundreds of cleistothecia were examined microscopically for the presence of ascospores.

${ }^{e}$ Recorded values represent the average from four cleistothecia of the percent of ascospores having germ tubes at $7.5 \mathrm{hr} \pm$ S.D.

failed to produce ascospores in a self-cross, four did not have the plasmid (Fig. 3, lanes 1-3,6). The fifth appeared to contain integrated plasmid (Fig. 3, lane 8) but remained defective in ascosporogenesis, possibly due to a DNA rearrangement. To test further for complete restoration of wild-type phenotype, we determined that the ascospore yield and viability were normal (data not shown) for one of the complemented transformants that had integrated pKK2.124.1 at the $\arg B$ locus. Because a wild-type copy of the $t u b B$ gene was fully able to complement the tubB $\Delta$ mutation in trans, we conclude that the $t u b B$ gene is essential for ascosporogenesis.

\section{Cytology of sexual development in wild-type and tubB $\Delta$ strains}

We set out to determine at what stage ascosporogenesis is blocked in the tubBA mutant. For these studies, we were required to make some preliminary cytological observations of sexual differentiation in wild-type strains, as this developmental stage has not been well documented in $A$. nidulans. The first visible sign of sexual differentiation is the appearance of thick-walled hülle cells that form a dense covering around the developing cleistothecium (Thom and Raper 1945; Benjamin 1955), enabling one to identify the fruiting bodies in the initial stages. We have observed by transmission electron microscopy (K. Kirk and N. Morris, unpubl.) that the central region of a cleistothecium is more mature than the outer region, suggesting that the fruiting bodies grow outwardly. Due to their relatively long maturation time ( 2-3 days), all of the developmental stages can be observed within a single growing cleistothecium (Elliott 1960).

For cytological studies, cleistothecia were harvested 24-36 hr after hülle cell formation was visible, and the contents were removed and mounted in fixative (see $\mathrm{Ma}$ terials and methods). The various stages of sexual development in wild-type fruiting bodies were photographed (Fig. 4B) and depicted schematically (Fig. 4A). One of the earliest stages is the establishment and maintainance of the dikaryon, a specialized hypha that forms an intertwined network. The dikaryotic hyphae consist of seg- 
ments having two haploid nuclei, each originating from the same parent in the case of self-fertilization, or from different parents in the case of cross-fertilization. At the time karyogamy occurs, the ascus mother cell can be seen to emerge as a small bud or, more often, as a swelling of the hyphal tip. This structure is the progenitor to the ascus, the sac in which the single diploid nucleus undergoes meiosis I and II. After meiosis, a mitotic division of the four haploid nuclei occurs, followed by free cell formation as spore walls are delineated. The ascospore walls become pigmented as they are formed; during this time, the nuclei undergo a second mitotic division. When the mature bright red ascospores are released, they contain two haploid nuclei.

Throughout this complex developmental process involving changes in cell shape, nuclear movement and fusion, and both meiotic and mitotic nuclear divisions, one can envision many requirements for functional microtubules. Cytological studies of cleistothecial development in the tubBA mutant revealed that although the time of appearance of the initial stages of development was slightly retarded, dikaryotic hyphae formed normally and propagated. These hyphae also differentiated to produce asci that enlarged to full size (Fig. 4C). Free cell formation within the asci, however, was never observed. Instead, the contents appeared to degenerate as time progressed, leaving an empty sac (Fig. 4D), which also subsequently degenerated.

We then analyzed the state of the nucleus within the ascus by staining with the DNA-specific fluorescent dye DAPI. The progression of the nuclei described above was readily observed in wild-type asci (Fig. 5A-F): after karyogamy (Fig. 5B), meiosis I (Fig. 5C), meiosis II (Fig. $5 D$ ), and after the first mitotic division and free cell formation (Fig. 5F). The red coloring of the spore walls can be detected by UV light (Fig. 5F) before it is evident by visible light (Fig. 5E); this pigmentation quenches the DAPI fluorescence in more mature ascospores, making it difficult to see the nuclei. Nuclear staining of the tubB $\Delta$ mutant revealed two nuclei in the dikaryon and one nuclear mass in the ascus mother cell (data not shown). This single nuclear mass persisted as the ascus grew to full size (Fig. 5G-J). More than a single nuclear mass was never observed in thousands of asci examined from $>50$ mutant cleistothecia, indicating that the $t u b B \Delta$ mutant was severely blocked before the first meiotic division.

Table 3. Cosegregation of tubB $\Delta$ with defect in ascosporogenesis

\begin{tabular}{lcr}
\hline & \multicolumn{2}{c}{ Ascosporogenesis $^{\mathrm{a}}$} \\
\cline { 2 - 3 } pyr & + & - \\
\hline+ & 0 & 25 \\
- & 25 & 0 \\
\hline
\end{tabular}

(Cosegregation) Cross between strains GR1 and KK2.70.7.

${ }^{2}$ Colonies formed from individual segregants were allowed to reach sexual maturity, and the contents of cleistothecia were examined microscopically for the presence of ascospores.

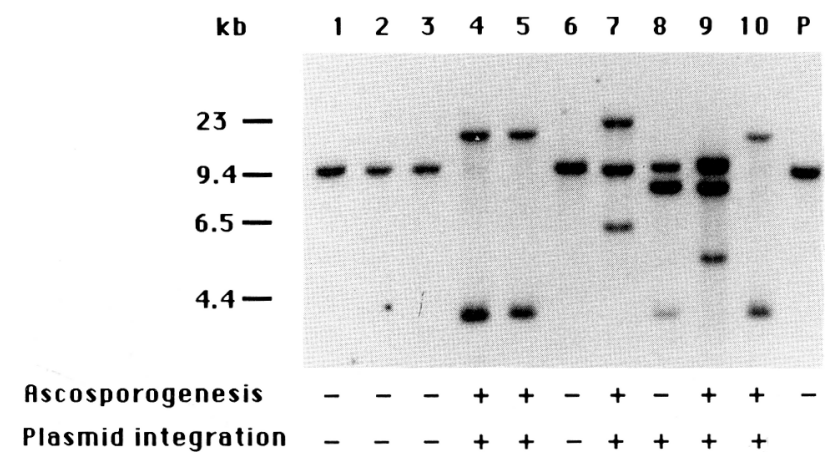

Figure 3. Ascosporogenesis was restored in $t u b B \Delta$ strains that had integrated a plasmid containing the wild-type $t u b B$ gene. Genomic DNA from the $t u b B \Delta$; $\arg B 2$ parent (lane $P$ ) and from recipients of plasmid pKK2.124.1 transformed to arginine prototrophy (lanes 1-10) was digested with $B a m H I$ and probed with radiolabeled DNA from the $\arg B$ gene. Colonies from each transformant were allowed to reach sexual maturity, and the contents of cleistothecia were microscopically examined for the presence of ascospores.

Frequently, the fluorescent mass was exceptionally large and bright (Fig. 5I); and although the amount of DNA cannot be accurately quantitated by the DAPI fluorescence, it is tempting to speculate that DNA synthesis was continuing in the mutant. A disperse red pigment was visible in the cytoplasm of many asci (Fig. 5J), indicating the advancement of other normal processes in sexual development. The pattern of the nuclear mass in this particular ascus suggests fragmentation or aborted division, but such an array was not frequently observed.

We conclude from cytological observations that the tubBS mutant established and propagated a dikaryon and that the two haploid nuclei migrated together. Furthermore, an ascus was formed and proceeded through at least some developmental processes, but the nuclear mass remained blocked at a stage prior to the first meiotic division. Because of the limits of resolution of the light microscope, these studies did not reveal whether the haploid nuclei were incompetent of karyogamy or whether karyogamy occurred and the resulting diploid nucleus was blocked in meiosis I.

\section{Discussion}

These studies were initiated to determine the function of the tubB $\alpha$-tubulin gene in $A$. nidulans. Expression of this gene during vegetative growth had been demonstrated previously (Weatherbee and Morris 1984). However, it was not known whether there was any functional consequence of this expression, because $t u b B$ had never been identified in any classic genetic studies. It was not until after the gene was cloned by hybridization to another $\alpha$-tubulin sequence (Doshi et al. 1991) that we could assign a role to $t u b B$ by using reverse genetics. In a previous disruption of the $t u b B$ gene, $20 \%$ of the coding region had been eliminated from the $3^{\prime}$ end; this partial disruption resulted in a lethal phenotype in hap- 

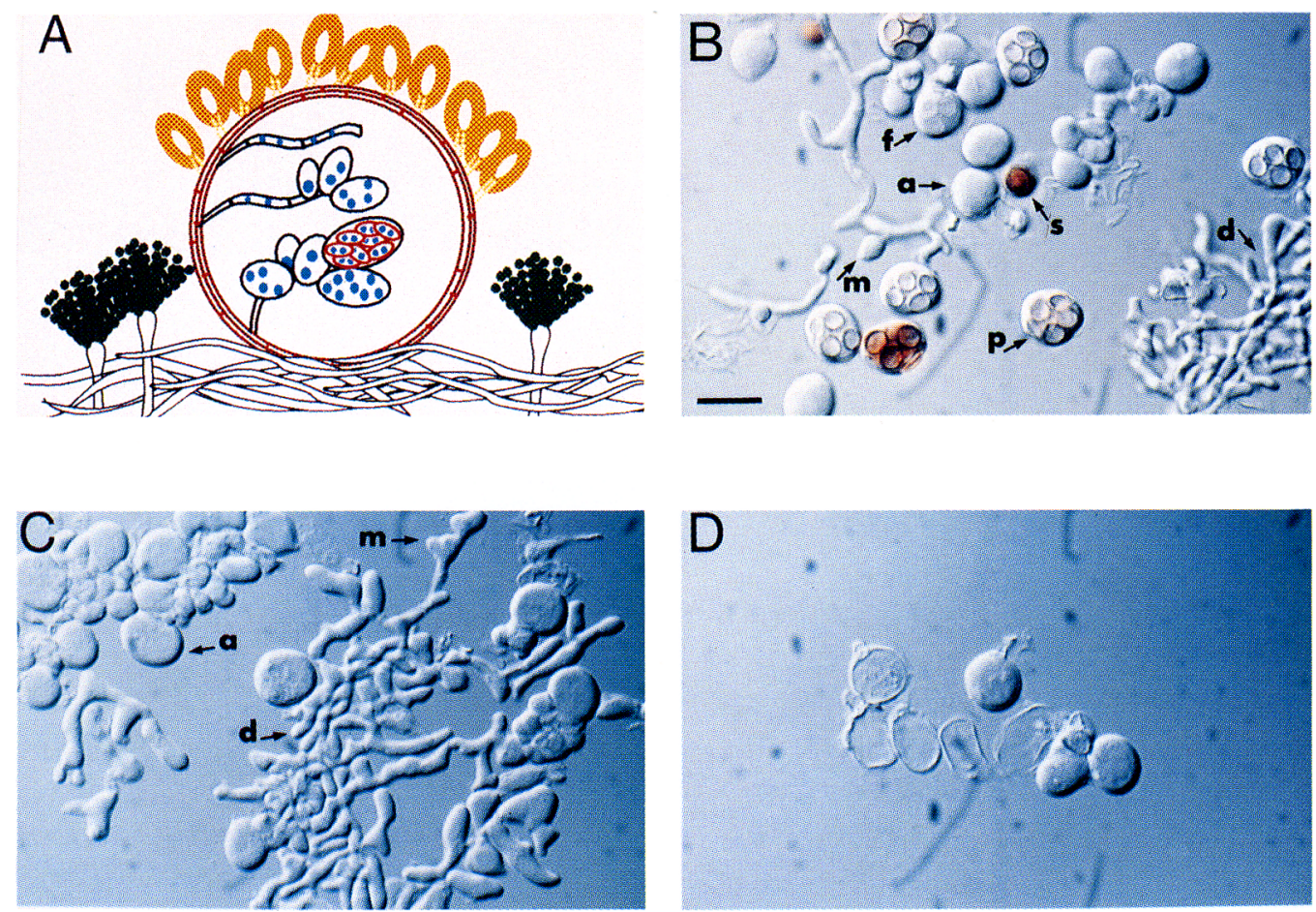

Figure 4. Cytology of sexual development. $(A)$ Schematic diagram illustrating the events that take place inside a growing wild-type cleistothecium and result in ascospore formation. Structures outside the cleistothecium are drawn to approximate scale: (green) conidia; (orange) hülle cells; (black lines) vegetative hyphae and conidiophores. The structures inside the cleistothecium are drawn to approximate scale relative to one another but are about two to three times larger than the external scale: (blue) nuclei; (red) wall pigmentation. Nomarski images of contents of a developing wild-type cleistothecium $(B)$, an early developing tubB $\Delta$ cleistothecium $(C)$, and a later developing $t u b B \Delta$ cleistothecium $(D)$ are shown. The arrows indicate dikaryotic hyphae $(\mathrm{d})$, ascus mother cell $(\mathrm{m})$, ascus $(\mathrm{a})$, free-cell formation $(\mathrm{f})$, early ascospore pigmentation $(\mathrm{p})$, and mature released ascospore $(\mathrm{s})$. Bar, $10 \mu \mathrm{m}$.

loid-germinating conidia (Doshi et al. 1991). The lack of a notable conidial or vegetative phenotype from the $t u b B \Delta$ allele presented in this paper suggests that the previous results may have been due to expression of a truncated $\alpha$-tubulin polypeptide.

Our results demonstrate that the $t u b B$ gene is not required until a specific stage of sexual differentiation is reached. Deletion of the $t u b B$ gene had no detectable effect on vegetative growth or asexual reproduction. At first glance, the $t u b B \triangle$ mutant appeared to initiate and potentiate sexual development: hülle cells formed normally, and a typical number of cleistothecia formed, became pigmented, and matured to full size. Nevertheless, ascosporogenesis did not occur within the fruiting bodies. Cytological studies on the contents of immature cleistothecia revealed that the $t u b B \Delta$ mutant was blocked at a stage prior to the first meiotic division. Because this defect was overcome by cross-fertilization to a $t u b B^{+}$ strain, only one functional $t u b B$ gene is required in the heterodikaryon to complete ascosporogenesis. We were unable to determine cytologically whether the block observed in a self-cross of the tubB $\Delta$ mutant was at the stage of haploid nuclear fusion or whether the block was in meiosis I. We attempted to clarify this problem by electron microscopy but were unable to embed the mutant fruiting bodies successfully.
tubB $\Delta$ is the first allele of a well-characterized gene shown to cause a specific cytological defect in sexual development in $A$. nidulans. A screen designed specifically to identify mutations affecting sexual fertility has not been utilized in $A$. nidulans but could lead to the understanding of a sophisticated developmental process. Such a screen has uncovered a number of important developmentally regulated genes in Saccharomyces cerevisiae. Among those characterized are genes required for chromosome recombination (Klapholz et al. 1985), chromosome segregation during meiosis (Wang et al. 1987), spore formation (Klapholz and Esposito 1980), and a number of early genes that regulate the onset of these processes in response to environmental conditions (for review, see Malone 1990). Additionally, a screen for mutations that suppress the $A$. nidulans tubB $\Delta$ allele could be readily established and may lead to the identification of important mutations in tubA, interacting $\beta$-tubulins or, possibly, meiotic-specific microtubule-associated proteins.

Why is the $t u b B$ gene essential for ascosporogenesis yet not required for vegetative growth or asexual reproduction? One answer may lie in the regulation of the two $\alpha$-tubulin genes. Tubulin gene families display complex arrays of differential gene expression throughout development in most organisms, and it has been proposed that 

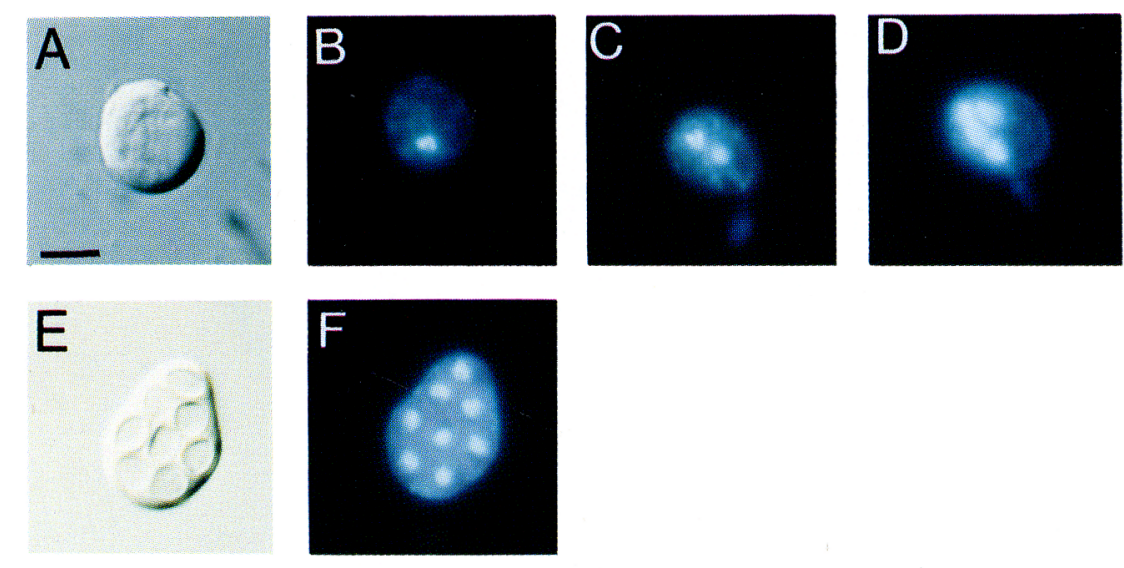

Figure 5. Cytology of ascus maturation in wild-type $(A-F)$ and the tubB $\Delta$ mutant $\mid G-$ I). The nuclei were observed by UV excitation of DAPI fluorescence, and those asci photographed in $B, F$, and $H$ were also photographed with Nomarski optics in $A, E$, and $G$, respectively. Bar, $5 \mu \mathrm{m}$.
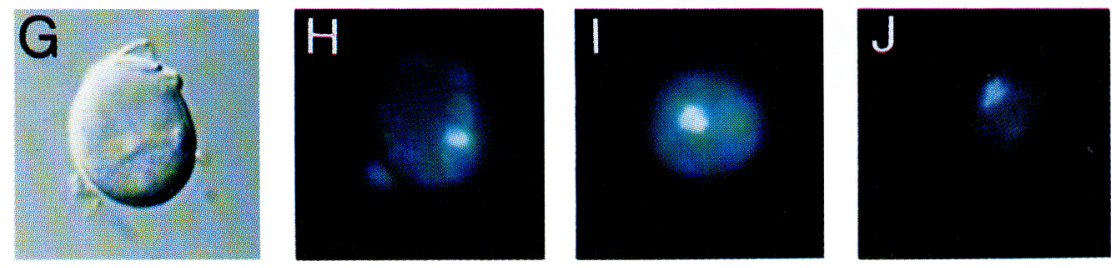

one reason for the evolution of multigene families may have been to fine-tune expression-temporally, spatially, and quantitatively (for review, see Raff 1984; Raff et al. 1987). One would then expect to see a correlation between the gene expression pattern and specific gene function during development. Such a situation has been clearly demonstrated in Drosophila melanogaster. Here, the $\beta_{2}$ gene, one of four encoding $\beta$-tubulin, is expressed solely during spermatogenesis and is the only member whose gene product appears in the developing male germ cells; null mutations have indicated that the $\beta_{2}$ gene is required for spermatid development, but is nonessential at all other times (Kemphues et al. 1979, 1982). The most elaborate arrays of tubulin gene expression are found in the vertebrates, which have many functional genes encoding $\alpha$ - and $\beta$-tubulin (for review, see Cleveland 1987). For example, specific tubulin genes are differentially expressed during neuronal development and repair (Hoffman and Cleveland 1988; Joshi and Cleveland 1989) and during differentiation of testis and muscle cells (Lewis and Cowan 1988).

Although the results of this study demonstrate that the $\operatorname{tubB} \alpha$-tubulin gene is essential for the completion of sexual development, they do not reveal whether the requirement for $t u b B$ is due to a differential regulation of the two $\alpha$-tubulin genes during this stage of the life cycle. Even though the tubA gene product constitutes the majority of $\alpha$-tubulin in vegetative hyphae (Weatherbee and Morris 1984), perhaps the tubA gene is not expressed after differentiation of the dikaryon; such a lack of expression would cause a total absence of $\alpha$-tubulin at this stage in $t u b B \Delta$ strains. On the contrary, perhaps the $t u b A$ gene is expressed throughout sexual differentiation but is incapable of up-regulating to meet a demand for more $\alpha$-tubulin during karyogamy or meiosis in strains lacking the $t u b B$ gene. Unfortunately, we have been unable to determine directly the expression pattern of the two $\alpha$-tubulin genes during sexual development. Differentiation is not synchronous within a cleistothecium, and we have been unable to find conditions where the dikaryotic hyphae will propagate outside the fruiting body (K. Kirk and N. Morris, unpubl.); therefore, we cannot quantitate the $t u b A$ and $t u b B$ expression levels in the dikaryon or ascus mother cell, where the requirement for the $t u b B$ gene is first evident.

An alternate, but not necessarily exclusive, explanation for the requirement of the $t u b B$ gene is that it encodes a specific isotype that is essential for a particular function in the developing ascus, such as proper formation of meiotic spindles. The two Aspergillus $\alpha$-tubulin genes encode proteins that are $28 \%$ divergent (Doshi et al. 1991), an unusually high degree of dissimilarity for two $\alpha$-tubulins within the same organism. It is therefore possible that some functional uniqueness lies in the primary amino acid sequence of the $t u b B \alpha$-tubulin. Interestingly, this gene encodes a glycine residue between what are usually the second and third codons in other known $\alpha$ - and $\beta$-tubulin genes; no alterations to the sequence of the first three residues have been identified for a tubulin in any other organism. This unique amino terminus may confer some structural specificity to the $t u b B$ protein. Alternatively, the amino terminus may have a function in the regulation of $t u b B$ expression. The first three residues of nascent vertebrate $\beta$-tubulin have been shown to be essential for cessation of the $\beta$-tubulin mRNA translation in response to an increase in unpolymerized tubulin subunits (Yen et al. 1988; Gay et al. 1989). If such a regulatory control exists for Aspergillus 
$\alpha$-tubulins, the tubB mRNA might be stable at times of microtubule depolymerization by virtue of the glycine insertion.

In summary, we have used reverse genetics to demonstrate that one of the two genes encoding $\alpha$-tubulin is essential for the developmental process of ascosporogenesis in A. nidulans. We are currently investigating the expression levels of the two $\alpha$-tubulin genes during sexual development by using an indirect approach; we are also determining whether the specific isotype encoded by the $t u b B$ gene is essential for ascosporogenesis.

\section{Materials and methods}

\section{Strains}

A. nidulans strains used in this study are as follows. GR5 (wA3; pyrG89; pyroA4) was used for transformation with the tubB deletion plasmid; KK2.150.1.10 (fwA1; tubBA::pyr4; pyrG89) and KK3.43.1 (yA2) were used for vegetative growth rate and conidiation studies; GR5, GR1 (yA2; pabaA1; pyrG89) and KK2.70.7 (wA3; tubBA::pyr4; pyrG89; pyroA4) were used for sexual fertility studies, KK2.140A.14 (fwA1; tubBA::pyr4; pyrG89; $\arg B 2$ ), a segregant from a cross of KK2.70.7 and 20.3.10 (fwA1; pyrG89; pabaA1; argB2) (courtesy of G.S. May), was used for complementation by the wild-type tubB plasmid; and KK2.150.1.10 and KK2.150.2.4 (fwA1; tubBA::pyr4; pyrG89;

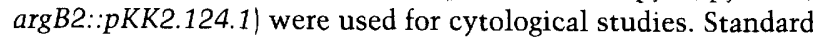
A. nidulans genetic techniques were used (Pontecorvo et al. 1953; Clutterbuck 1974; Cove 1977). Escherichia coli strain $\mathrm{DH} 5 \alpha \mathrm{F}^{\prime}$ was used for plasmid maintenance.

\section{Plasmids}

Plasmids were constructed by using standard techniques (Sambrook et al. 1989). pKK2.1.3, used to delete the $t u b B$ gene, is depicted in Figure 6. A 3.2-kb SphI fragment from pDP6031 (Doshi et al. 1991), containing the 3' $500 \mathrm{bp}$ of the $t u b B$ gene lof which $240 \mathrm{bp}$ is coding) and the pUC19 vector, was isolated,

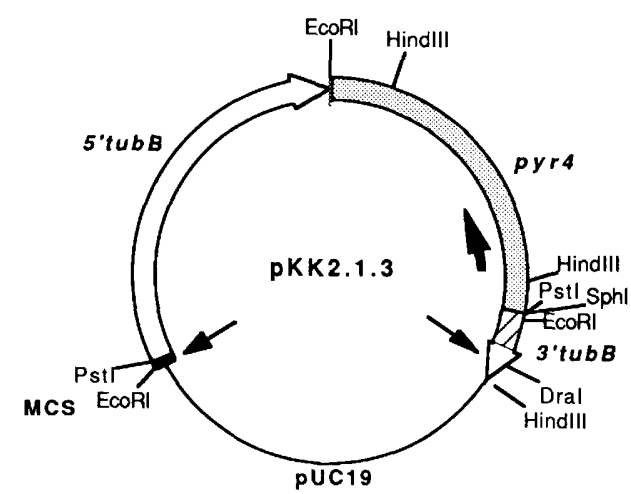

Figure 6. Schematic diagram of the plasmid used to delete the $t u b B$-coding region. The open curved arrow represents the $5^{\prime}$ and 3 '-genomic sequences flanking the $t u b B$-coding region; the hatched area represents the $3^{\prime} 20 \%$ of the $t u b B$-coding region. The bold line represents the pUC19 multiple cloning site (MCS). The stippled curved area represents the pyr4 selectable marker; the bold arrow indicates the direction of transcription. The two smaller arrows indicate the sites of restriction enzyme digestion prior to $A$. nidulans transformation. circularized, and subsequently linearized with PstI in the multiple cloning site. This was used as the vector for the ligation of a 4.9-kb Pst I fragment from pDP723 (courtesy of P. Doshi) containing a $2.7-\mathrm{kb}$ PstI-EcoRI 5' genomic flanking sequence from the $t u b B$ gene in pDP6031 joined to a $2.2-\mathrm{kb}$ SmaI-PstI fragment containing the pyr4 gene from pODC (Waring et al. 1989). A plasmid having the insert in the correct orientation was digested with DraI in the $3^{\prime}$-flanking sequence and $X b a I$ in the multiple cloning site prior to $A$. nidulans transformation to increase the efficiency of gene replacement.

pKK2.124.1, used to complement the tubBD mutation, was constructed as follows. A $5.5-\mathrm{kb}$ HindIII genomic fragment from pDP6031 (Doshi et al. 1991), containing the tubB-coding region with $2.8-\mathrm{kb}$ upstream sequence and $0.5-\mathrm{kb}$ downstream sequence, was isolated and cloned into the SmaI site in the polylinker of pMOO6 (courtesy of G.S. May), a pUC plasmid containing a 3.3-kb $X b a I$ fragment from the Aspergillus argB gene (Miller et al. 1985).

\section{A. nidulans transformation}

A. nidulans transformation was carried out as described previously (Osmani et al. 1987). Protoplasts for transformations to uridine prototrophy were plated on solid YAG media $10.5 \%$ yeast extract, $2 \%$ glucose, $2 \%$ agar, trace elements| supplemented with $0.6 \mathrm{M} \mathrm{KCl}$, and protoplasts for transformations to arginine prototrophy were plated on minimal media (Kafer 1977) supplemented with $0.6 \mathrm{M} \mathrm{KCl}$.

\section{Isolation and analysis of A. nidulans genomic DNA}

Aspergillus genomic DNA was isolated as described previously (Raeder and Broda 1985). Subsequent manipulations utilized standard techniques (Sambrook et al. 1989). DNA from transformants was either boiled and loaded onto a dot blot apparatus containing Hybond-N nylon membrane (Amersham, Arlington Heights, IL) or digested with restriction enzymes, separated by agarose gel electrophoresis, and transferred to Hybond- $\mathrm{N}$ nylon membranes. The manufacturer's recommendations were followed for transfer and binding of DNA to membranes. DNA probes used for hybridizations were radiolabeled by using a random oligonucleotide primer kit (Pharmacia, Piscataway, NJ) according to manufacturer's instructions. The hybridization probe described in Figure 1 was a 350-bp SphI-DraI fragment from the 3 ' end of the $t u b B$ gene in pDP6031 (Doshi et al. 1991), containing $240 \mathrm{bp}$ of coding region and $110 \mathrm{bp}$ of 3 '-untranslated region. The probes described in Figure 2 were a $1.7-\mathrm{kb}$ BamHI-SphI fragment from pDP6031 containing the $5^{\prime} 80 \%$ of the tubBcoding region and a 2.4-kb $B a m H I$ fragment from pDP485 (Doshi et al. 1991) containing the entire tubA-coding region. The probe used for Figure 3 was a 3.3-kb $X b a I$ fragment from pMOO6 containing the $\arg B$ gene. All hybridizations were at $65^{\circ} \mathrm{C}$, and washes were in $0.1 \times$ SSPE, $0.1 \%$ SDS at $65^{\circ} \mathrm{C}$.

\section{Determination of growth rate and ascospore yield and viability}

Growth rate was determined by inoculating conidia onto YAG solid media or YAG solid media containing the indicated concentrations of benomyl (gift from DuPont de Nemours \& Co., Inc.) and allowing germination and growth to proceed at the indicated temperatures for $24 \mathrm{hr}$. The increase in colony diameter (in millimeters) was then measured daily for 3 days. Ascospore yield was determined by clearing four large cleistothecia of hülle cells and conidia, opening them individually in water, and counting an aliquot of the ascospores obtained from each in 
a Petroff Hauser counting chamber. In the case of the tubBA mutant, whole crushed cleistothecia were also examined microscopically. Ascospore viability was determined by germinating the ascospores at $37^{\circ} \mathrm{C}$ for $7.5 \mathrm{hr}$ on solid YAG media appropriately supplemented for nutritional requirements and microscopically scoring 200 from each cleistothecium for the presence of germ tubes.

\section{Manipulations of developing cleistothecia and cytology}

Immature cleistothecia were removed from the colony $24-36 \mathrm{hr}$ after focal accumulations of hülle cells were evident. The conidia and hülle cells were removed by carefully rolling the developing fruiting bodies on a $4 \%$ agar plate. The contents were then removed by piercing the translucent shell with a drawnout glass rod and teasing out the fleshy tissue. This material was mounted immediately in fixative $15 \%$ glutaraldehyde, $0.2 \%$ Triton X-100, $100 \mathrm{mM} \mathrm{KPO}_{4}$ ) containing 4',6-diamidino-2-phenylindole $(0.25 \mu \mathrm{g} / \mathrm{ml}$ of DAPI; Sigma $)$ The cells were photographed with a Zeiss Axioplan microscope with Nomarski optics.

\section{Acknowledgments}

We are grateful to Dr. Peter Mirabito for illuminating discussions throughout the course of the research and preparation of the manuscript, and we thank Dr. Prasanta Chakraborty and Michelle Mischke for critical comments on the manuscript. We thank Dr. Annmarie Enos for technical advice, Dr. Herbert Geller for the use of his microscope, and Dr. Michael McCarthy for the use of his computer. We also thank Drs. Mervyn Turner and Roy Smith at Merck, Sharp, and Dohme Research Laboratories for their continued support. This research was supported by a National Institutes of Health grant to N.R.M. (GM29228) and by a Merck predoctoral fellowship to K.E.K.

The publication costs of this article were defrayed in part by payment of page charges. This article must therefore be hereby marked "advertisement" in accordance with 18 USC section 1734 solely to indicate this fact.

\section{References}

Benjamin, C.R. 1955. Ascocarps of Aspergillus and Penicillium. Mycologia 47: 669-687.

Champe, S.P. and L.D. Simon. 1991. Cellular differentiation and tissue formation in the fungus Aspergillus nidulans. In Morphogenesis: An analysis of the developmental biology of structures (ed. E.F. Rosomando and A. Stephen), Marcel Dekker Inc., New York (In press.)

Cleveland, D.W. 1987. The multitubulin hypothesis revisited: What have we learned? I. Cell Biol. 104: 381-383.

Clutterbuck, A.J. 1974. Aspergillus nidulans In Handbook of genetics (ed. R.C. King), pp. 447-510. Plenum Publishing, New York.

Cove, D.J. 1977. The genetics of Aspergillus nidulans. In The genetics and physiology of Aspergillus nidulans (ed. J.E. Smith and J.A. Pateman), pp. 81-95. Academic Press, London.

Doshi, P., C.A. Bossie, J.H. Doonan, G.S. May, and N.R. Morris. 1991. Two alpha-tubulin genes of Aspergillus nidulans encode divergent proteins. Mol. Gen. Genet. 225: 129-141.

Elliot, C.G. 1960. The cytology of Aspergillus nidulans. Genet. Res. Camb. 1: 462-476.

Gay, D.A., S.S. Sisodia, and D.W. Cleveland. 1989. Autoregulatory control of beta-tubulin mRNA stability is linked to translation elongation. Proc. Natl. Acad. Sci. 86: 5763-5767.
Hoffman, P.N. and D.W. Cleveland. 1988. Neurofilament and tubulin expression recapitulates the developmental program during axonal regeneration: Induction of a specific beta-tubulin isotype. Proc. Natl. Acad. Sci. 85: 4530-4533.

Joshi, H.C. and D.W. Cleveland. 1989. Differential utilization of beta-tubulin isotypes in differentiating neurites. J. Cell Biol. 109: 663-673.

Kafer, E. 1977. Meiotic and mitotic recombination in Aspergillus and its chromosomal aberrations. Adv. Genet. 19: $33-$ 131.

Kemphues, K.J., R.A. Raff, T.C. Kaufman, and E.C. Raff. 1979. Mutation in a structural gene for a beta-tubulin specific to testis in Drosophila melanogaster. Proc. Natl. Acad. Sci. 76: 3991-3995.

Kemphues, K.J., T.C. Kaufman, R.A. Raff, and E.C. Raff. 1982. The testis specific beta-tubulin subunit in Drosophila melanogaster has multiple functions in spermatogenesis. Cell 31: 655-670.

Klapholz, S. aud R.E. Esposito. 1980. Isolation of SPO12-1 and SPO13-1 from a natural varient of yeast that undergoes a single meiotic division. Genetics 96: 567-588.

Klapholz, S., C.S. Waddell, and R.E. Esposito. 1985. The role of the SPO11 gene in meiotic recombination in yeast. Genetics 110: $187-216$.

Lewis, S.A. and N.J. Cowan. 1988. Complex regulation and functional versatility of mammalian alpha- and beta-tubulin isotypes during the differentiation of testis and muscle cells. I. Cell Biol. 106: 2023-2033.

Malone, R.E. 1990. Dual regulation of meiosis in yeast. Cell 61: 375-378.

May, G.S. and N.R. Morris. 1988. Developmental regulation of a conidiation specific beta-tubulin in Aspergillus nidulans. Dev. Biol. 128: 406-414.

May, G.S., J. Gambino, J.A. Weatherbee, and N.R. Morris. 1985. Identification and functional analysis of beta-tubulin genes by site specific integrative transformation in Aspergillus nidulans. I. Cell Biol. 101: 712-719.

Miller, B.L., K.Y. Miller, and W.E. Timberlake. 1985. Direct and indirect gene replacements in Aspergillus nidulans. Mol. Cell. Biol. 5: 1714-1721.

Morris, N.R., J.A. Weatherbee, J. Gambino, and L.G. Bergen. 1984. The tubulins of Aspergillus nidulans: Genetics, biochemistry, and function. In Molecular biology of the cytoskeleton (ed. G. Borisey, D. Cleveland, and D. Murphy), pp. 211-222. Cold Spring Harbor Laboratory, Cold Spring Harbor, New York.

Oakley, B.R. and N.R. Morris. 1980. Nuclear movement is betatubulin-dependent in Aspergillus nidulans. Cell 19: 255262 .

- . 1981. A beta-tubulin mutation in Aspergillus nidulans that blocks microtubule function without blocking assembly. Cell 24: 837-845.

Oakley, B.R., C.E. Oakley, and J.E. Rinehart. 1987. Conditionally lethal tubA alpha-tubulin mutations in Aspergillus nidulans. Mol. Gen. Genet. 208: 135-144.

Oakley, C.E. and B.R. Oakley. 1989. Identification of gammatubulin, a new member of the tubulin superfamily encoded by the mipA gene of Aspergillus nidulans. Nature 338: 662664.

Osmani, S.A., G.S. May, and N.R. Morris. 1987. Regulation of the mRNA levels of $\operatorname{nim} A$, a gene required for the G2-M transition in Aspergillus nidulans. $J$. Cell Biol. 104: 14951504.

Pontecorvo, G., J.A. Roper, C.M. Hemmons, K.D. MacDonald, and A.W.J. Bufton. 1953. The genetics of Aspergillus nidulans. Adv. Genet. 5: 141-238. 
Raeder, U. and P. Broda. 1985. Rapid preparation of DNA from filamentous fungi. Lett. Appl. Microbiol. 1: 17-20.

Raff, E.C. 1984. Genetics of microtubule systems. J. Cell Biol. 99: $1-10$.

Raff, E.C., H.B. Diaz, H.D. Hoyle, J.A. Hutchens, M. Kimble, R.A. Raff, J.E. Rudolph, and M.A. Subler. 1987. Origins of multiple gene families: Are there both functional and regulatory constraints? In Development as an evolutionary process (ed. R.A. Raff and E.C. Raff), pp. 203-238. A.R. Liss, New York.

Sambrook, J., E.F. Fritsch, and T. Maniatis. 1989. Molecular cloning: A laboratory manual, 2nd ed. Cold Spring Harbor Laboratory Press, Cold Spring Harbor, New York.

Sheir-Neiss, G., M.H. Lai, and N.R. Morris. 1978. Identification of a gene for beta-tubulin in Aspergillus nidulans. Cell 15: 639-647.

Thom, C. and K.B. Raper. 1945. A manual of the Aspergilli. Wiliams and Wilkins, Baltimore, MD.

Timberlake, W.E. 1980. Developmental gene regulation in $A s$ pergillus nidulans. Dev. Biol. 78: 497-510.

- 1990. Molecular genetics of Aspergillus development. Annu. Rev. Genet. 24: 5-36.

Wang, H.T., S. Frackman, J. Kowalisyn, R.E. Esposito, and R. Elder. 1987. Developmental regulation of SPO13, a gene required for separation of homologous chromosomes at meiosis I. Mol. Cell. Biol. 7: 1425-1435.

Waring, R.B., G.S. May, and N.R. Morris. 1989. Characterization of an inducible expression system in Aspergillus nidulans using alcA and tubulin-coding genes. Gene 79: 119130.

Weatherbee, J.A. and N.R. Morris. 1984. Aspergillus contains multiple tubulin genes. J. Biol. Chem. 259: 15452-15459.

Weatherbee, J.A., G.S. May, J. Gambino, and N.R. Morris. 1985. Involvement of a particular species of beta-tubulin (beta 3) in conidial development in Aspergillus nidulans. $J$. Cell Biol. 101: 706-711.

Yen, T.J., P.S. Machlin, and D.W. Cleveland. 1988. Autoregulated instability of beta-tubulin mRNAs by recognition of the nascent amino terminus of beta-tubulin. Nature 334: 580-585. 


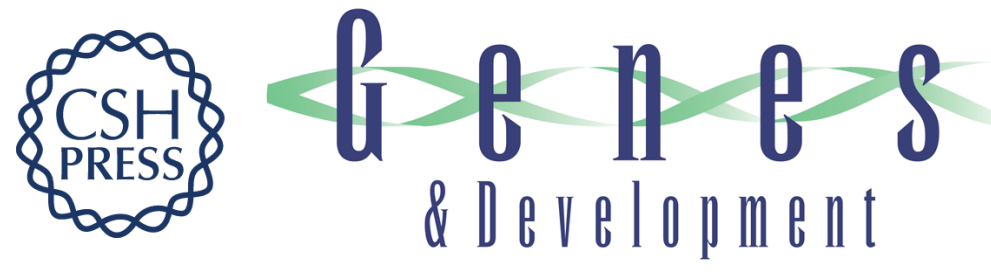

\section{The tubB alpha-tubulin gene is essential for sexual development in Aspergillus nidulans.}

K E Kirk and N R Morris

Genes Dev. 1991, 5:

Access the most recent version at doi:10.1101/gad.5.11.2014

References This article cites 33 articles, 15 of which can be accessed free at:

http://genesdev.cshlp.org/content/5/11/2014.full.html\#ref-list-1

License

Email Alerting

Service

Receive free email alerts when new articles cite this article - sign up in the box at the top right corner of the article or click here.

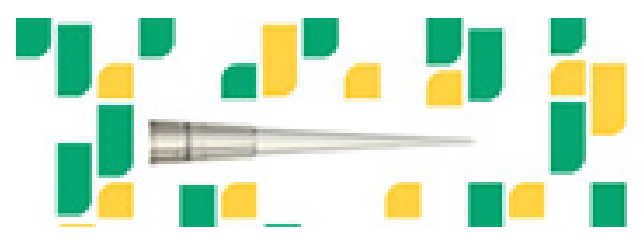

Focused on your science.

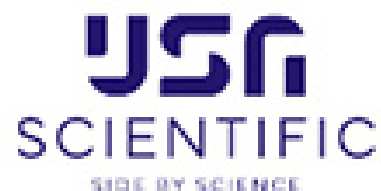

Copyright (c) Cold Spring Harbor Laboratory Press 